\title{
Selenocysteine in Trypanosoma evansi: Identification of the Genes selb, selc, seld, pstk, seltryp and the Selenophosphate Synthetase Protein
}

\author{
Kaio Cesar Simiano Tavares ${ }^{\mathrm{a}, \mathrm{b}}$, Maria Gabriela Casagrande Dambrós ${ }^{\mathrm{a}}$, André Saraiva Leão \\ Antunes $^{b}$, Pietro Martin Danziato ${ }^{b}$, Patricia Hermes Stoco ${ }^{c}$, Aline Daiane Schlindwein ${ }^{c}$, Renato \\ Simões Moreira ${ }^{\mathrm{a}, \mathrm{d}}$, Luiz Claudio Miletti ${ }^{\mathrm{a}}$ \\ a Laboratório de Hemoparasitas e Vetores Centro de Ciências Agroveterinárias (CAV), Universidade do Estado de Santa Catarina \\ (UDESC). Av. Luís de Camões, 2090, Conta Dinheiro, Lages, SC, 88520-000 Brazil \\ ${ }^{\mathrm{b}}$ Experimental Biology Center (NUBEX), Universidade de Fortaleza. Av. Washington Soares, 1321 - Edson Queiroz, Fortaleza -CE \\ 60811-905, Brazil \\ ${ }^{\mathrm{c}}$ Laboratório de Protozoologia, Universidade Federal de Santa Catarina, Florianópolis. SC. Brazil \\ d Instituto Federal de Santa Catarina (IFSC), Campus Lages, R. Heitor Villa Lobos, 222, São Francisco, Lages - SC, 88506-400 \\ Brazil
}

\begin{abstract}
Selenoproteins have been described in all three domains of life and their function has been mainly associated with oxidative stress defense. Canonical elements required for selenoprotein production have been identified in members of the kinetoplastid group supporting the existence of a complete selenocysteine synthesis pathway in these organisms. Currently, nothing is known regarding the selenocysteine pathway in Trypanosoma evansi. In this study, we identified the expression of the elements selB, selC, selD, PSTK and selTRYP at the mRNA level in T. evansi. All translated proteins (selD, PSTK, selTRYP and selB) have the domains predicted and higher identity with Trypanosoma brucei. gambiense. The selenophosphate synthetase protein was localized in the cytoplasm. Our results support the existence of an active selenocysteine pathway in T. evansi.
\end{abstract}

Keywords: Trypanosoma evansi, selenocysteine, selB, selC, selD, PSTK, seltTRYP.

\section{INTRODUCTION}

Trypanosoma evansi is the pathogenic trypanosomatid with the widest distribution worldwide, pos-

Address for correspondence: Luiz Claudio Miletti, Departamento de Produção Animal e Alimentos, Centro de Ciências Agroveterinárias, Universidade do Estado de Santa Catarina, Av. Luiz de Camões, 2090 Bairro Conta Dinheiro, Lages, SC, 88520-000, Brazil. Phone: +55 49 3289-9175. E-mail: luiz.miletti@udesc.br. ORCID 0000-0001-5926-0286 ing a health threat to livestock and causing economic losses in Africa, South America, Asia and Oceania (Desquesnes et al. 2013; Salah et al. 2015; Kumar et al. 2017). Nonspecific mechanical vectors ubiquitous to most environments can transmit $T$. evansi, which it is the etiologic agent of the disease known as surra. The disease, characterized by anemia, fever, widespread subcutaneous edema and a marked ataxia in the hindlimbs, affects almost all species of mammals (Silva et al. 2002), including humans (Joshi et al. 2005), and is distinct from the diseases caused by closely related 
trypanosomes such as T. brucei and T. equiperdum (Desquesnes et al. 2013).

The incorporation of selenium into proteins is an important metabolic pathway described in all three domains of life and its function has been mainly associated with oxidative stress defence (Papp et al. 2007). Selenium is used in the form of the amino acid selenocysteine, which is cotranslationally incorporated in a complex, context-specific manner into nascent polypeptides at UGA codons (Mangiapane et al. 2014). In bacteria, the biosynthesis and insertion of selenocysteine in proteins is associated with four genes: selA, selB, selC and selD (Leinfelder et al. 1988). In eukaryotes, among the key elements in this pathway are a signaling nucleotide structure in the messenger RNA (SECIS), a specific tRNA (tRNA ${ }^{\mathrm{Sec}}$, product of the selC gene) and protein complexes such as selenophosphate synthetase (SPS, product of selD gene) and a GTP-dependent elongation factor that is specific for Sec incorporation (EF-Sec, product of $\mathrm{selB}$ gene). There is no homolog for selA in eukaryotes, however, the enzymes O-phosphoseryl-tRNASec kinase (PSTK gene) and O-phosphoseryl-tRNA( $\mathrm{Sec})$ selenium transferase (SepSecS gene) acts in serine phosphorylation and selenocysteylation (Geslain et al. 2006). These elements allow the conversion of selenium to its organic form, its aminoacylation into tRNA ${ }^{\mathrm{Sec}}$ and the coupling of nucleotidic at the UGA codon for the insertion of selenocysteine into the protein (Allmang et al. 2009). Canonical elements required for selenoprotein production have been identified in members of the kinetoplastid group, supporting the existence of a complete selenocysteine synthesis pathway in these organisms (Cassago et al. 2006). In T. brucei three selenoprotein genes were found; one of them, seltryp, has not been found in any other organism so far (Cassago et al. 2006; Geslain et al. 2006; Lobanov et al. 2006; Sculaccio et al. 2008; Aeby et al. 2009a). For $T$. evansi, due to their great similarity with $T$. brucei the elements of selenoprotein metabolism must be present. Thus, given the relevance of this parasite in health and economics and the importance of this pathway for the parasite, this study aimed to identify elements of the selenocysteine pathway in T. evansi, and verifying the occurrence of substantial differences between them.

\section{MATERIALS AND METHODS}

\section{Animal infection and parasite purification}

The T. evansi strain used in this study was isolated from a naturally infected dog in southern Brazil (Colpo et al. 2005), characterized (Duarte et al. 2014) and stored in liquid nitrogen until a rat (Rattus norvegicus) was experimentally inoculated with 108 trypomastigotes by intraperitoneal injection. Parasitemia was estimated daily by blood smear examination under the microscope. Slides were mounted with blood collected from the tail vein, stained by the panoptic method and visualized at a $1000 \times$ magnification. When parasitemia reached $>80$ trypanosomes per field, the rat was anesthetized with Zoletil ${ }^{\circledR}$ (Fort Dodge ${ }^{\circledR}$ Ingelheim am Rhein, Germany) using 20-40 mg/kg and blood containing parasites was collected by cardiac puncture. Parasites were separated from blood by centrifugation with HEPES buffered Percoll ${ }^{\circledR}$ (GE Healthcare $\AA$ Chicago, USA) according to the technique described by Grab \& Bwayo (1982). Trypanosomes were separated from white blood cells using DEAE-Cellulose (Sigma Aldrich ${ }^{\circledR}$ Saint Louis, USA) chromatography with PBS-Glucose by the method previously described by Lanham \& Godfrey (1970). Purified parasites were used in the following procedures. The procedures described were approved by the Animal Welfare Committee of Santa Catarina State University (UDESC), number 1.30.11, in accordance to Brazilian laws and ethical principles published by the Conselho Nacional de Controle de Experimentação Animal (CONCEA).

\section{Gene expression and sequencing}

Total RNA was extracted from $T$. evansi using Trizol ${ }^{\circledR}$ reagent (Invitrogen ${ }^{\circledR}$ Carlsbad, USA), according to the manufacturer's instructions. Complementary strand (cDNA) synthesis was performed using the ProtoScript M-MuLV First Strand cDNA Synthesis ${ }^{\circledR}$ kit (New England Biolabs ${ }^{\circledR}$ Ipswich, USA). PCRs were performed employing specific primers, as shown in Table 1. Primer pairs were designed based on T. brucei gene sequences for selB (XM_839239), selC (DQ508818), selD (XM_818071), PSTK (XM_818060) and selTRYP (XM_839398) deposited in GenBank. PCR products were resolved in $1 \%$ agarose gel, cloned into pGEM using the pGEM-TEasy kit (Promega ${ }^{\circledR}$, Madison, USA) and sequenced.

\section{Bioinformatic Analysis}

The identities of cloned sequences were confirmed using BLAST tool (www.ncbi.nlm.nih.gov/blast) and ORF were translated with the Expasy Translate tool (http://expasy.org/tools/dna.html). selC tRNA secondary structure was obtained using ARAGORN software (http://130.235.46.10/aragorn/). Amino acid sequences were aligned with sequences of related species using the ClustalX software (Thompson et al. 1997) and domain analysis was performed using Conserved Domain Search (http://www.ncbi.nlm.nih. gov/Structure/cdd/) and InterProScan (http://www.ebi.ac.uk/Tools/ InterProScan/) tools (data not shown).

The bioinformatic processes used a set of 5 strains downloaded from TryTripDB (http://tritrypdb.org/tritrypdb/): T. evansi (STI805), T. brucei (TREU927), T. b. gambiense (DAL972), T. vivax (Y486) and T. equiperdum (5694) this last one downloaded from NCBI under the ID number txid5694 (https://www.ncbi.nlm. nih.gov/genome/?term=txid5694). 
A FASTA file containing the selD (TevSTIB805.10.9990), selB (TevSTIB805.4.1890), PSTK (TevSTIB805.10.9870) and selTRYP (TevSTIB805.4.3500) genes, was used to search for orthologous genes in the above related strains through of Orthovenn software (www.bioinfogenome.net/OrthoVenn/) with parameters E-value $1 \mathrm{e}-5$ and Inflation value 1.5. The orthologous genes on the selD, selB, PSTK and selTRYP genes identified had the similarity analysis done through the BLASTp online tool (https://blast.ncbi.nlm. nih.gov/). The orthologous sequences were then aligned using the MEGA7 software using the ClustalW method, with the default parameters of the tool, to construct the phylogenetic tree through the Maximum Likehood method, and this tree was plotted by the Interactive Tree of Life (iTOL) tool.

A search of the PFAM database (https://pfam.xfam.org/) was performed through HMMER (available at https://www.ebi.ac.uk/ Tools/hmmer/) to identify the domains of the selD, selB, PTSK and selTRYP proteins.

The identified domains were separated according to the position indicated in the search and the domains of each protein in T. evansi were compared by BLAST with other trypanosomatids species.

\section{Immunodetection of selenophosphate synthetase}

Immunolocalization of selenophosphate synthetase protein (SPS), which is coded by the selD gene in T. evansi, was performed using indirect immunofluorescence. Purified parasites were fixed in paraformaldehyde $4 \%$ and distributed on immunofluorescence slides. Slides were washed with $0.1 \%$ PBS-Tween and 5\% skimmed dry milk for 1 hour. Next, the parasites were incubated 1 hour with a mouse anti-SPS primary polyclonal antibody against $T$. brucei SPS (kindly provided by Dr. Otavio H. Thiemman) diluted 1:100 and 15 minutes with the anti-IgG mouse conjugate Alexa Fluor $488^{\circledR}$ (Invitrogen ${ }^{\circledR}$ Carlsbad, USA) diluted 1:1000. Images were obtained using an Olympus fluorescence microscope model BX40-FL.
Western Blot for SPS detection was performed with the same polyclonal antibody used in the immunofluorescence assay. $50 \mu \mathrm{g}$ of total protein extract from purified T. evansi were separated on a $12 \%$ SDS-PAGE and transferred to a nitrocellulose membrane. Nonspecific sites on the membrane were blocked for 1 hour with $5 \%$ skimmed dry milk in blocking buffer $(10 \mathrm{mM}$ Tris- $\mathrm{HCl}, \mathrm{pH} 8$; $120 \mathrm{mM} \mathrm{NaCl}, 0.05 \%$ Tween-20). SPS protein was detected by incubating for 2 hours with the anti-SPS-antibody diluted 1:500 and 2 hours with the anti-mouse $\operatorname{IgG}$ conjugated with alkaline phosphatase (Sigma Aldrich ${ }^{\circledR}$ Saint Louis, USA) diluted 1:30000. The membrane was incubated with the NBT/BCIP solution (Sigma Al$\operatorname{drich}^{\circledR}$ Saint Louis, USA) in $190 \mathrm{mM}$ Tris base, $1 \mathrm{mM} \mathrm{MgCl}$ until color appeared.

\section{RESULTS}

Sequencing, translation and domain analysis of Trypanosoma evansi genes selB, selC, selD, PSTK and selTRYP

Expression of key genes of the selenocysteine pathway in $T$. evansi was demonstrated following parasite purification by DEAE-cellulose chromatography, RNA extraction and sequencing. PCR performed on cDNA using specific primer pairs for selB, selC, selD, PSTK and selTRYP revealed bands with the predicted sizes for each gene (Figure 1). Our sequencing results, performed with a brazilian T. evansi strain (Colpo et al. 2005), did not differ from the deposited at the TritrypDB.

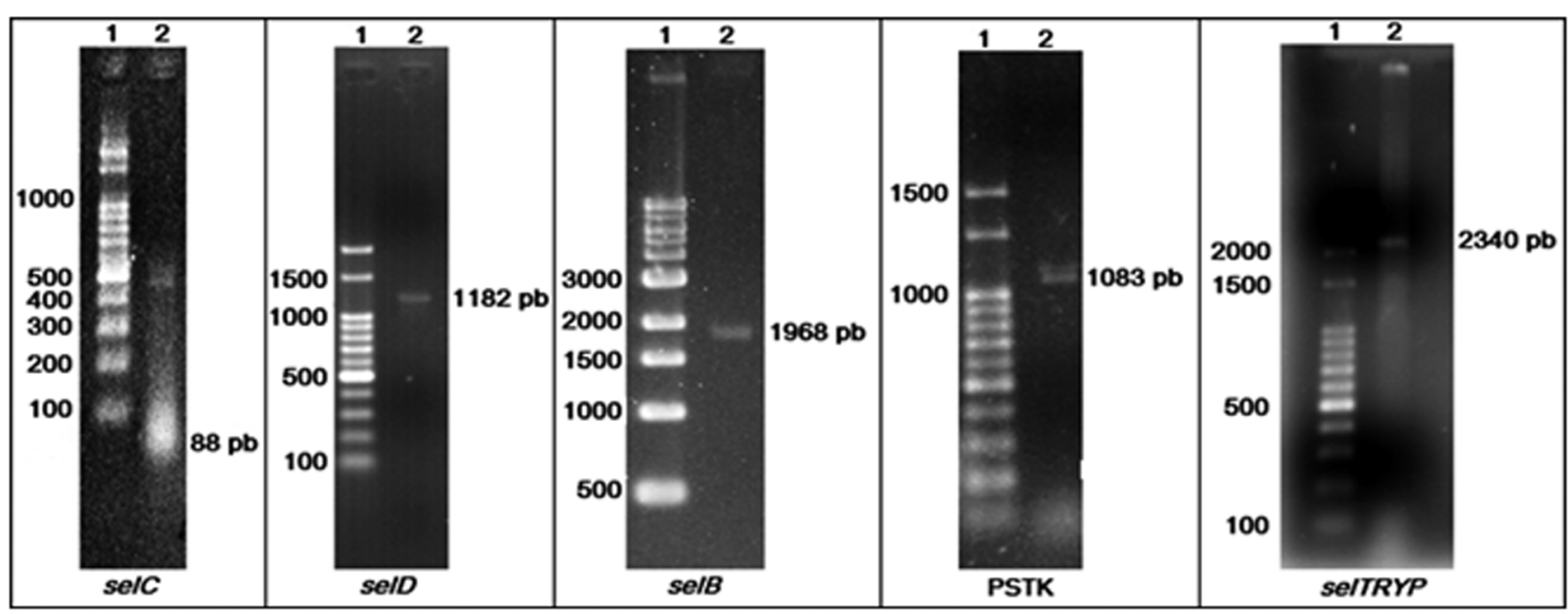

Fig. 1. Detection of gene expression of the selenocysteine pathway in T. evansi. Numbers on the sides indicate molecular size in base pairs. Lanes marked as 1: Molecular-weight size marker (100bp lader Ludwig Biotecnologia- Brazil); Lanes marked as 2: PCR product. selD, selB and selTRYP amplicons ran in 1\% agarose gels; selC and PSTK ran in 2\% agarose gels. The gene amplified in each reaction is indicated on the bottom. 
Table 1. Oligonucleotide primer sequence used in PCR and RT-PCR assays.

\begin{tabular}{|c|c|c|c|c|}
\hline ORF & Primer & Sequence $\left(5^{\prime}-3^{\prime}\right)$ & Amplicon size(bp) & References \\
\hline \multirow[t]{2}{*}{ selB } & selBF & $\begin{array}{l}\text { GCC CAT ATG ACA GAA GTT AAT GAT GTT GCC TCT G } \\
\text { GCC CTC TGA GCT ACT GCT GAA GCT GAC TGT G }\end{array}$ & 1968 & Cassago et al. 2006 \\
\hline & selBR & & & \\
\hline \multirow[t]{2}{*}{ selC } & selCF & $\begin{array}{l}\text { GCC ACG ATG AGC TCA GCT GGT GCT G } \\
\text { CAC CAC AAA GGC CGA ATC GAA CGG C }\end{array}$ & 88 & Cassago et al. 2006 \\
\hline & selCR & & & \\
\hline \multirow[t]{2}{*}{ selD } & selDF & $\begin{array}{l}\text { ACG TAC GTC ATA TGT CAG AGA AGG AAG GAA AAG TAA } \\
\text { TAC }\end{array}$ & 1182 & Sculaccio et al. 2008 \\
\hline & selDR & $\begin{array}{l}\text { ATC TGA GCT ATC AAA TAA TCT ATC ATT TAC CTT CGC } \\
\text { TCC CA }\end{array}$ & & \\
\hline \multirow[t]{2}{*}{ PSTK } & PSTKF & CCC ATA TGA CAG TTT GTC TTG TTC TAC TAA & 1083 & designed by authors \\
\hline & PSTKR & CCC TCT GAG TTA TCA AAG ATC TAC TAA GGC ATG A & & \\
\hline \multirow[t]{2}{*}{ selTRYP } & seltrypF & TAT AAA GGA TCC ATG GTT TCT GAA GC & 2340 & Lobanov et al. 2006 \\
\hline & seltrypR & AAG AGT AAG CTT TTA CCT GGG TCA GC & & \\
\hline
\end{tabular}

All the T. evansi proteins (translated from the sequencing results of the selD, PSTK, selTRYP and selB T. evansi genes) were compared against proteins from related organisms. The highest identity of the T. evansi proteins was with T. $b$. gambiense and the lowest with T. vivax (Table 2, Figure 2). All proteins were found in the five species, except selTRYP that is not present in T. equiperdum (Table 2). Molecular phylogenetic analysis shows that $T$. vivax proteins are the most different related to other proteins and there are a close relationship among T. evansi and T. b. gambiense and among T. brucei and T. equiperdum proteins (Figure 2).

For the SelB (TevSTIB805.4.1890), SelD (TevSTIB805.10.9990) and PSTK (TevSTIB805.10.9870) proteins, domains with the characteristics described in Table 3 were found. In addition, the identities found of each protein with other trypanosomatids are also demonstrated.

Sequence and domain analysis of the predicted proteins for the 3 coding genes selB, selD and PSTK revealed regions with characteristic properties for each expected activity. Domain analysis of $\mathrm{selB}$ protein (selenocysteine-specific elongation factor, EFSec), revealed GTP binding (PF00009.27) and 50S ribosome-binding GTPase (PF01926.23). selD product, SPS, showed conserved regions among protozoans, a non-specific aminoimidazole ribonucleotide synthetase (AIRS) suggested as a putative ATP binding domain. (Miller et al. 1999). PSTK, the third selenoprotein-coding gene identified in $T$. evansi presented great similarity with sequences of several species described by Carlson et al. (2004), especially at the $\mathrm{N}$-terminal portion. Domain analysis revealed that $T$. evansi PSTK gene product belongs to ATPases associated with diverse cellular activities are a protein family sharing a common conserved module of approximately 230 amino acid residues (Koonin et al. 2004). Only a partial sequence was obtained for selTRYP gene, which was found to have $99 \%$ similarity with the hypothetic protein Tb927.4.3410, described by Lobanov et al. (2006) as T. brucei selTRYP. Further analysis of T. brucei selTRYP coding sequence revealed a rhodanese-like domain, which is found in some dehydrogenases and stress-related proteins (Bordo \& Bork 2002), as well as a CXXU motif, which is related to antioxidant activity and present in most selenoproteins (Dikiy et al. 2007).

selC nucleotide sequence analysis using ARAGORN tRNA gene prediction tool (http://130.235.46.10/ ARAGORN/) revealed the presence of a D-loop, an anticodon loop, a variable loop, a TwC loop and an acceptor stem, suggesting that selC codes for a functional tRNA molecule (Figure 3). In addition, sequence alignment with the selC gene from T. brucei, T. cruzi and Leishmania major revealed a high degree of similarity among these species (97\% and 90\%, respectively).

\section{Demonstration of presence and cellular localization of the selenophosphate synthetase protein in $T . e v$ - ansi}

To determine the presence and cellular localization of the selenophosphate synthetase protein, encoded by the selD gene, western blot and immunocytochemistry staining was performed in fixed cells and cellular extracts of $T$. evansi. SPS was detected as an approximate- 

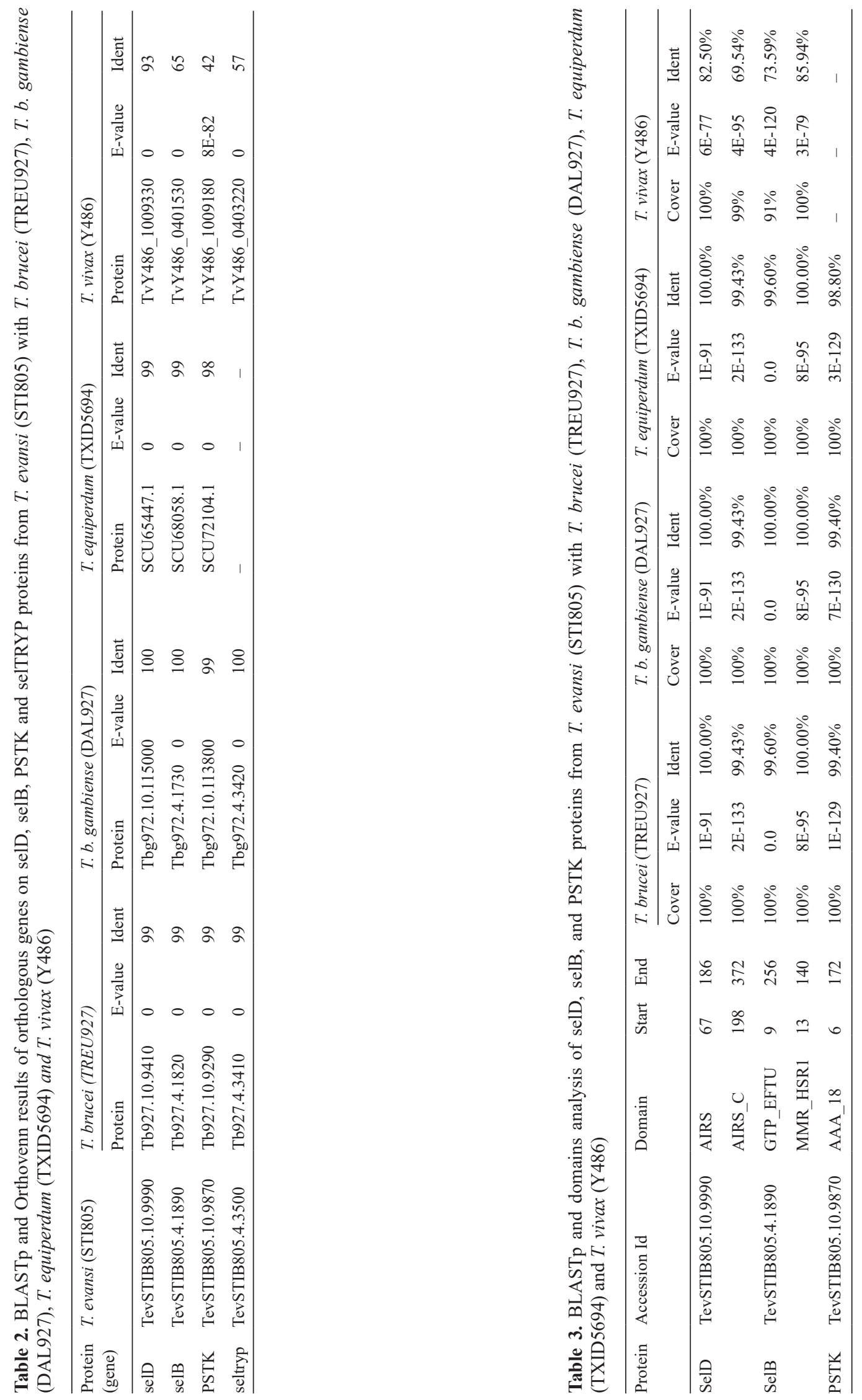


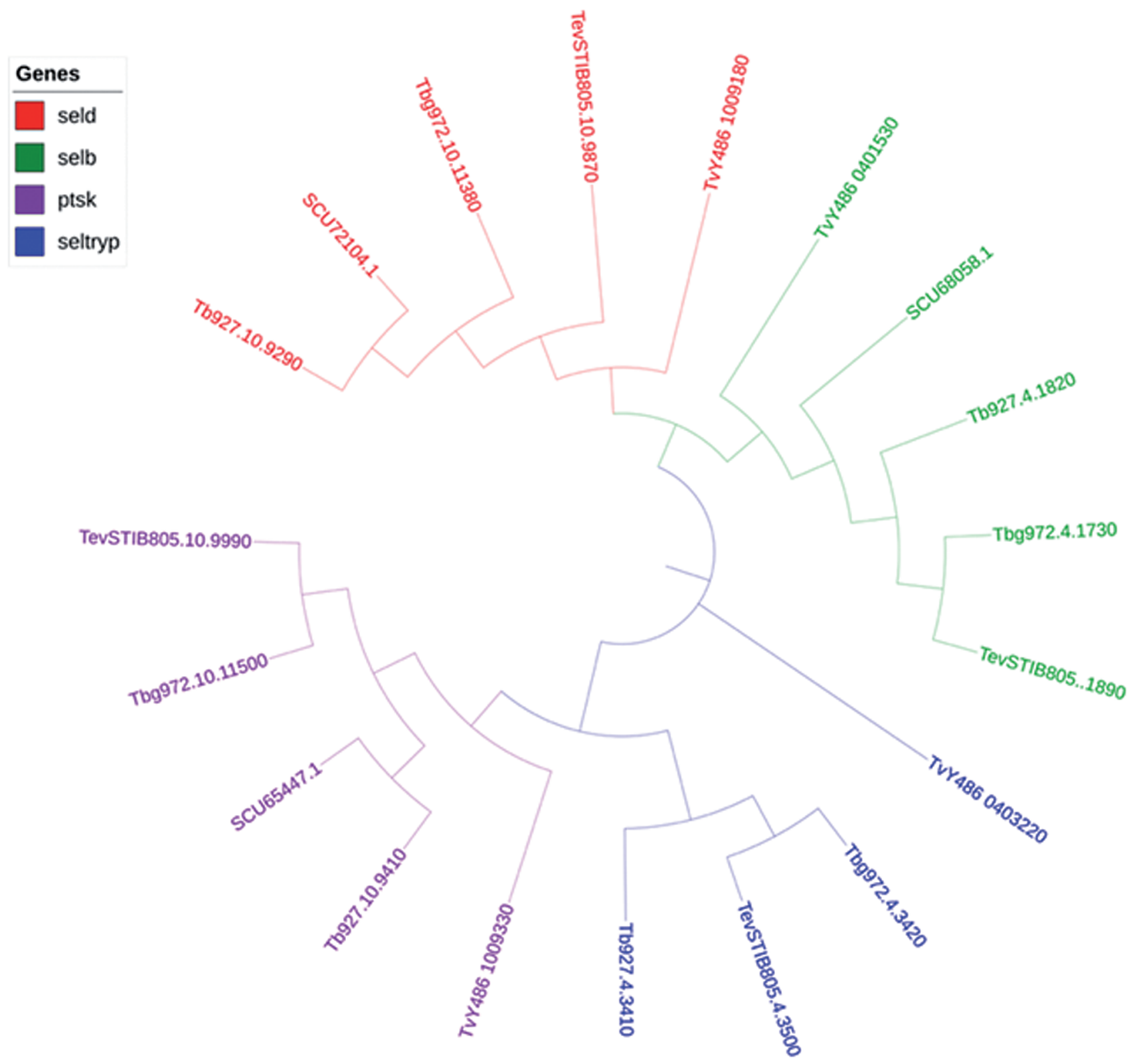

Fig. 2. Molecular phylogenetic analysis by Maximum Likehood method generated in Mega 7 and Plotted in iTOL (Interactive Tree of Life). selD (red), selB (green), PSTK (purple), selTRYP (blue). Protein (gene) codes correspond to those described in Table 2.

ly $43 \mathrm{kDa}$ band in the western blot (Figure 4A) with an extranuclear location (Figure 4B). Furthermore, DAPI staining highlighted the lack of kinetoplast DNA in this T. evansi, a hallmark used to distinguish it from other closely related protozoans such as T. brucei.

\section{DISCUSSION}

The selenocysteine inserting system is a metabolic pathway present in the three domains of life, with components demonstrated in the proteomes of eukaryotes, archaea and prokaryotes (Lobanov et al. 2006). Trypanosomal orthologues of this pathway have been identified in several members of the kinetoplastid group 


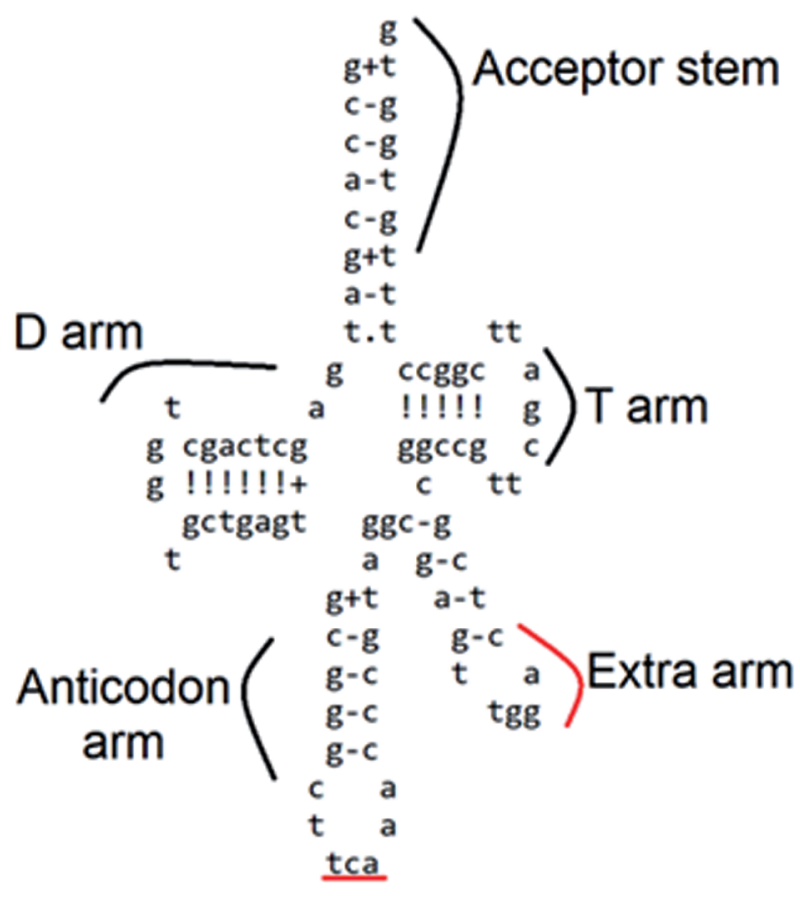

Fig. 3. Secondary structure of $T$. evansi tRNA ${ }^{\mathrm{Sec}}$ simulated with ARAGORN. Highlighted in red are the anticodon TCA and the elongated extra arm that are characteristic of the specific tRNA for selenocysteine.
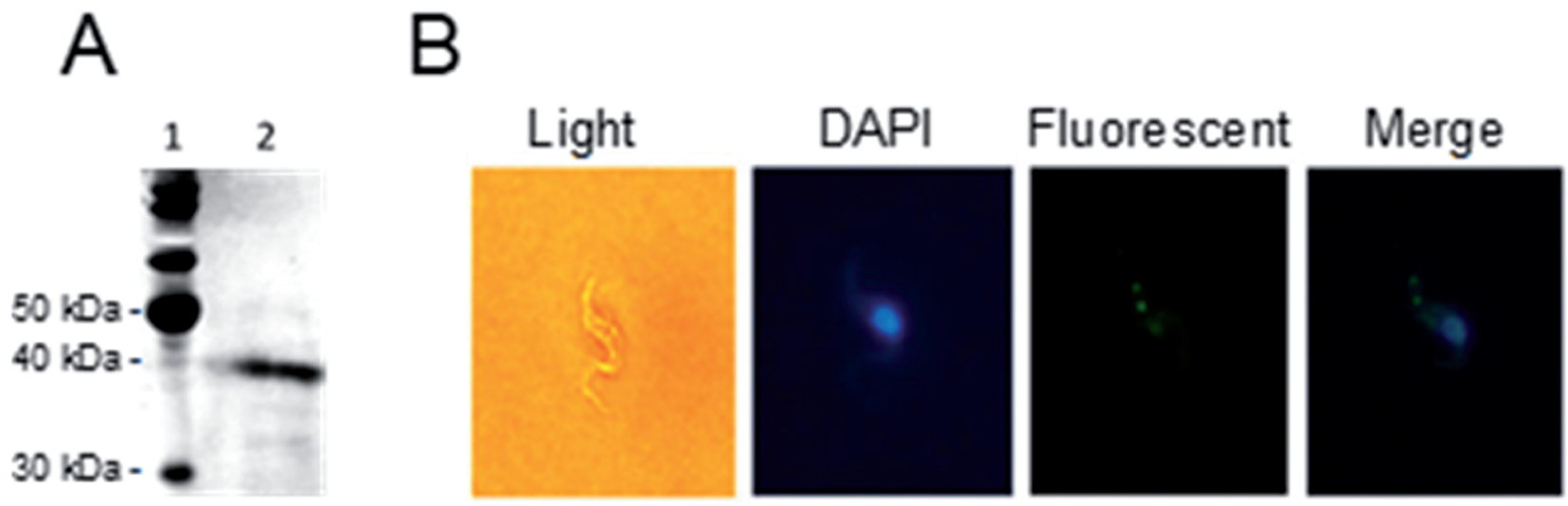

Fig. 4. Detection and cellular localization of the SPS protein, encoded by the selD gene, in T. evansi. A) Detection of $43 \mathrm{kDa}$ SPS by western blot T. evansi cellular extracts blotted with an anti-SPS antibody. Lane 1 - Protein Ladder, Lane 2 - T. evansi total protein extract. B) Immunocytochemistry analysis on fixed $T$. evansi for the determination of SPS extranuclear cellular localization.

(Cassago et al. 2006; Bouzaidi-Tiali et al. 2007; Geslain et al. 2006; Sculaccio et al. 2008), however none of its elements have yet been described in $T$. evansi. Here, we successfully identified key selenocysteine pathway genes in T. evansi with evidence of selB, selC, PSTK, selTRYP expression at the RNA level and of selenophosphate synthetase (product of selD gene) at the protein level. Coding sequence analyses of $T$. evansi genes revealed the presence of conserved domains among protozoans and higher organisms, consistent with the presence of a functional selenocysteine inserting system in this parasite. Taken together, our data demonstrate that $T$. evansi expresses key elements of the selenocysteine inserting system suggesting the parasite's ability to incorporate the micronutrient selenium into selenoproteins.

One of the major functions of selenoproteins is to confer resistance against reactive oxygen species (ROS) and most selenoproteins contain a CxxU motif that predicts this redox role (Papp et al. 2007). We 
identified the expression of the trypanosomatid exclusive selenoprotein gene selTRYP (Lobanov et al. 2006) in $T$. evansi, which strongly suggests the utilization of selenoproteins by this parasite. Furthermore, conserved regions and domains are present in key elements of the selenocisteine pathway. selB gene sequence codes for regions typical for tRNA elongation factors such as GTP binding and $\beta$-ribosomal barrier regions (Bulteau \& Chavatte 2015). selD product, SPS, presents ATP binding domains (Itoh et al. 2009b) and localizes to the cytoplasm. PSTK presents protein kinase domains and selC secondary structure prediction shows it shares most features present in eukaryotic tRNASec (Carlson et al. 2004; Itoh et al. 2009a; Aeby et al. 2010).

The absence of kinetoplast DNA (Ventura et al. 2002), the extensive philogenetics analysis of T. evansi and T. brucei (Carnes et al. 2015) and the high similarity of the five selenoproteins metabolis genes sequences identified in this study to T. brucei sequences corroborates the most accepted hypothesis about the origins of $T$. evansi from a gradual loss of kDNA in T. brucei (Jensen et al. 2008).

The identification of selenoprotein genes in kinetoplastida is relevant from an evolutionary perspective as they have been identified in the three domains of life but are absent in plants and fungi (Mariotti et al. 2019). Thus, the identification and characterization of genes related to the selenocysteine pathway in T. evansi can shed further light into the evolution of selenium utilization (Lobanov et al. 2006).

Studies have reported that the selenocysteine pathway is not essential for parasite survival under nonstress conditions as knockout cells for O-phosphoseryl-tRNA(Sec) selenium transferase (SepSecS), SPS or PSTK do not show impaired growth or infectivity (Bonilla et al. 2016). Aeby et al. (2009b) showed that T. brucei is highly sensitive to auranofin, a complex that targets selenoproteins, but so are SepSecS knockout cells, indicating that the trypanocidal effect may not be related to selenoproteins. Interestingly, Costa et al. (2011) reported impaired growth in SPS knockdown cells exposed to continuous oxidative stress. However, the experiments were carried out in T. brucei, not $T$. evansi. Thus, it remains to be determined whether T. evansi selenoproteins or specific components of this pathway can be potential drug targets. This is a possibility, since despite very close genetic identity among members of the kinetoplastid group (Carnes et al. 2015; Richardson et al. 2017), each species presents a myriad of morphophysiological differences, including host specificity, life cycle and disease symptoms upon infection indicating that small genetic changes can bring about significant phenotypical differences.

These facts encourage further investigations into whether the selenocysteine insertion pathway can be a potential novel therapeutic target for T. evansi.

Funding Information: Kaio Cesar Simiano Tavares was a fellowship of Coordenadoria de Aperfeiçoamento de Pessoal de Nível Superior (CAPES- Brazil). This work was supported by Conselho Nacional de Desenvolvimento Científico e Tecnológico (CNPqBrazil) Processo 578122/2008-1.

Conflict of interest: On behalf of all authors, the corresponding author states that there is no conflict of interest.

\section{REFERENCES}

Aeby E., Palioura S., Pusnik M., et al. (2009a) The canonical pathway for selenocysteine insertion is dispensable in Trypanosomes. Proc. Natl. Acad. Sci. USA 106: 5088-92. https://doi. org/10.1073/pnas.0901575106

Aeby E., Seidel V., Schneider A. (2009b) The selenoproteome is dispensable in bloodstream forms of Trypanosoma brucei. Mol. Biochem. Parasitol. 168: 191-193. https://doi.org/10.1016/j. molbiopara.2009.08.007

Aeby E., Ullu E., Yepiskoposyan H., et al. (2010) tRNASec is transcribed by RNA polymerase II in Trypanosoma brucei but not in humans. Nucleic Acids. Res. 38: 5833-5843. https://doi. org/10.1093/nar/gkq345

Allmang C., Wurth L., Krol A. (2009) The selenium to selenoprotein pathway in eukaryotes: more molecular partners than anticipated. Biochim. Biophys. Acta 1790: 1415-23. https://doi. org/10.1016/j.bbagen.2009.03.003

Bonilla M., Krull E., Irigoín F., et al. (2016) Selenoproteins of African trypanosomes are dispensable for parasite survival in a mammalian host. Mol. Biochem. Parasitol. 206: 13-19. https://doi.org/10.1016/j.molbiopara.2016.03.002

Bordo D., Bork P. (2002) The rhodanese/Cdc25 phosphatase superfamily. Sequence-structure-function relations. EMBO Rep. 3: 741-746

Bouzaidi-Tiali N., Aeby E., Charrière F., et al. (2007) Elongation factor 1a mediates the specificity of mitochondrial tRNA import in T. brucei. EMBO J. 26: 4302-12. https://doi.org/10.1038/ sj.emboj.7601857

Bulteau A. L., Chavatte L. (2015) Update on Selenoprotein Biosynthesis. Antioxid. Redox. Signal. 23: 775-794. https://doi. org/10.1089/ars.2015.6391

Carlson B. A., Xu X. M., Kryukov G. V., et al. (2004) Identification and characterization of phosphoseryl-tRNA[Ser]Sec kinase. Proc. Natl. Acad. Sci. USA 101: 12848-12853. https:// doi.org/10.1073/pnas.0402636101

Carnes J., Anupama A., Balmer O., et al. (2015) Genome and Phylogenetic Analyses of Trypanosoma evansi Reveal Extensive Similarity to T. brucei and Multiple Independent Origins for Dyskinetoplasty. PLoS Negl. Trop. Dis. 9:e3404. https://doi. org/10.1371/journal.pntd.0003404

Cassago A., Rodrigues E. M., Prieto E. L., et al. (2006) Identification of Leishmania selenoproteins and SECIS element. Mol. Biochem. Parasitol. 149: 128-134. https://doi.org/10.1016/j. molbiopara.2006.05.002 
Colpo C. B., Monteiro S. G., Stainki D. R., Colpo E. T. B, Henriques G. B. (2005) Infecção natural por Trypanosoma evansi em cães. Ciên. Rur. 35, 717-719

Costa F. C., Oliva M. A. V, De Jesus T. C. L., et al. (2011) Oxidative stress protection of Trypanosomes requires selenophosphate synthase. Mol. Biochem. Parasitol. 180: 47-50. https://doi. org/10.1016/j.molbiopara.2011.04.007

Desquesnes M., Dargantes A., Lai D-H, et al. (2013) Trypanosoma evansi and Surra: A Review and Perspectives on Transmission, Epidemiology and Control, Impact, and Zoonotic Aspects. Biomed. Res. Int. 2013: 1-20. https://doi.org/10.1155/2013/321237

Dikiy A., Novoselov S. V., Fomenko D. E., et al. (2007) SelT, SelW, SelH, and Rdx 12: Genomics and molecular insights into the functions of selenoproteins of a novel thioredoxin-like family. Biochemistry 46: 6871-6882. https://doi.org/10.1021/ bi602462q

Duarte D. P., Tavares K. C. S., Lazarrotto C. R., et al. (2014) Genetic Profile of Two isolates of Trypanosoma evansi from Southern Brazil with different parasitaemias. Biotemas 27: 73-80. https:// doi.org/10.5007/2175-7925.2014v27n3p73

Geslain R., Aeby E., Guitart T., et al. (2006) Trypanosoma seryltRNA synthetase is a metazoan-like enzyme with high affinity for tRNASec. J. Biol. Chem. 281: 38217-38225. https://doi. org/10.1074/jbc.M607862200

Grab D. J., Bwayo J. J. (1982) Isopycnic isolation of African trypanosomes on Percoll gradients formed in situ. Acta Trop. 39: 363-366

Itoh Y., Chiba S., Sekine S. I., Yokoyama S. (2009a) Crystal structure of human selenocysteine tRNA. Nucleic Acids Res. 37: 6259-6268. https://doi.org/10.1093/nar/gkp648

Itoh Y., Sekine S. ichi, Matsumoto E., et al. (2009b) Structure of Selenophosphate Synthetase Essential for Selenium Incorporation into Proteins and RNAs. J. Mol. Biol. 385: 1456-1469. https:// doi.org/10.1016/j.jmb.2008.08.042

Jensen R. E., Simpson L., Englund P. T. (2008) What happens when Trypanosoma brucei leaves Africa. Trends Parasitol. 24: 428431

Joshi P. P., Shegokar V. R., Powar R. M., et al. (2005) Human trypanosomiasis caused by Trypanosoma evansi in India: the first case report. Am. J. Trop. Med. Hyg. 73: 491-5

Kumar R., Jain S., Kumar S., Sethi K., Kumar S., Tripathi B. N. (2017) Impact estimation of animal trypanosomosis (surra) on livestock productivity in India using simulation model: current and future perspective. Vet Parasitol Reg Stud Reports 10: 1-12

Koonin E. V., Aravind L., Leipe D. D., Iyer L. M. (2004). Evolutionary history and higher order classification of AAA ATPases. J. Struct. Biol. 146 (1-2): 11-31. doi:10.1016/j.jsb.2003.10.010

Lanham S. M., Godfrey D. G. (1970) Isolation of salivarian trypanosomes from man and other mammals using DEAE-cellulose. Exp. Parasitol. 28: 521-534. https://doi.org/10.1016/00144894(70)90120-7

Leinfelder W., Forchhammer K., Zinoni F., Sawers G., MandrandBerthelot M. A., Böck A. (1988) Escherichia coli genes whose products are involved in selenium metabolism. J. Bacteriol. 170(2): $540-6$
Lobanov A. V., Gromer S, Salinas G., Gladyshev V. N. (2006) Selenium metabolism inTrypanosoma: Characterization of selenoproteomes and identification of a Kinetoplastida-specific selenoprotein. Nucleic Acids Res. 34: 4012-4024. https://doi. org/10.1093/nar/gk1541

Lun Z. R., Fang Y., Wang C. J., Brun R. (1993) Trypanosomiasis of domestic animals in China. Parasitol. Today 9: 41-45

Mangiapane E., Pessione A., Pessione E. (2014) Selenium and selenoproteins: an overview on different biological systems. Curr. Protein. Pept. Sci. 15: 598-607

Mariotti M., Salinas G., Gabaldón T., Gladyshev V. N. (2019) Utilization of selenocysteine in early-branching fungal phyla. Nat. Microbiol. 4(5): 759-765

Mueller E. J., Oh S., Kavalerchik E., et al. (1999) Investigation of the ATP binding site of Escherichia coli aminoimidazole ribonucleotide synthetase using affinity labeling and site-directed mutagenesis. Biochemistry 38: 9831-9839. https://doi. org/10.1021/bi990638r

Papp L. V, Lu J., Holmgren A., Khanna K. K. (2007) From selenium to selenoproteins: synthesis, identity, and their role in human health. Antioxid. Redox. Signal. 9: 775-806. https://doi. org/10.1089/ars.2007.1528

Richardson J. B., Lee K. Y., Mireji P., et al. (2017) Genomic analyses of African Trypanozoonstrains to assess evolutionary relationships and identify markers for strain identification. PLoS Negl. Trop. Dis. 11:e0005949. https://doi.org/10.1371/journal. pntd.0005949

Salah A. A., Robertson I., Mohamed A. (2015) Estimating the economic impact of Trypanosoma evansi infection on production of camel herds in Somaliland. Trop. Anim. Health Prod. 47: 707-714. https://doi.org/10.1007/s11250-015-0780-0

Sculaccio S. A., Rodrigues E. M., Cordeiro A. T., et al. (2008) Selenocysteine incorporation in Kinetoplastid: Selenophosphate synthetase (SELD) from Leishmania major and Trypanosoma brucei. Mol. Biochem. Parasitol. 162: 165-171. https://doi. org/10.1016/j.molbiopara.2008.08.009

Silva R. A. M., Seidl A., Ramirez L., Dávila A. M. R. (2002) Trypanosoma evansi e Trypanosoma vivax: Biologia Diagnóstico e Controle. Embrapa Pantanal, Corumbá, Mato Grosso, Brazil 141

Tuntasuvan D., Jarabrum W., Viseshakul N., et al. (2003) Chemotherapy of surra in horses and mules with diminazene aceturate. Vet. Parasitol. 110: 227-233.https://doi.org/10.1016/S03044017(02)00304-7

Ventura R. M., Takeda G. F., Silva R. A. M. S., et al. (2002) Genetic relatedness among Trypanosoma evansi stocks by random amplification of polymorphic DNA and evaluation of a synapomorphic DNA fragment for species-specific diagnosis. Int. J. Parasitol. 32: 53-63. https://doi.org/10.1016/S00207519(01)00314-9

Received on $6^{\text {th }}$ January, 2021; revised on $10^{\text {th }}$ May, 2021; accepted on $14^{\text {th }}$ June, 2021 